\title{
Unilateral cutaneous congestion induced by Valsalva manoeuvre due to vascular malformation
}

\author{
Kohei Hirose, Takanobu Hirosawa, Taro Shimizu
}

Dokkyo Medical University, Tochigi, Japan

\section{Correspondence to}

Dr Taro Shimizu,

shimizutaro7@gmail.com

Accepted 25 February 2017

\section{DESCRIPTION}

A man aged 37 years presented with hip osteoarthritis with avascular femoral head necrosis due to chronic alcohol use. He had spinal arteriovenous fistula (AVF) which was diagnosed with spinal angiography (figure 1A, B) and spinal MRI (figure 2) 30 years prior. The lesion was not completely treated by surgical intervention at that time. On examination, Valsalva manoeuvre showed a
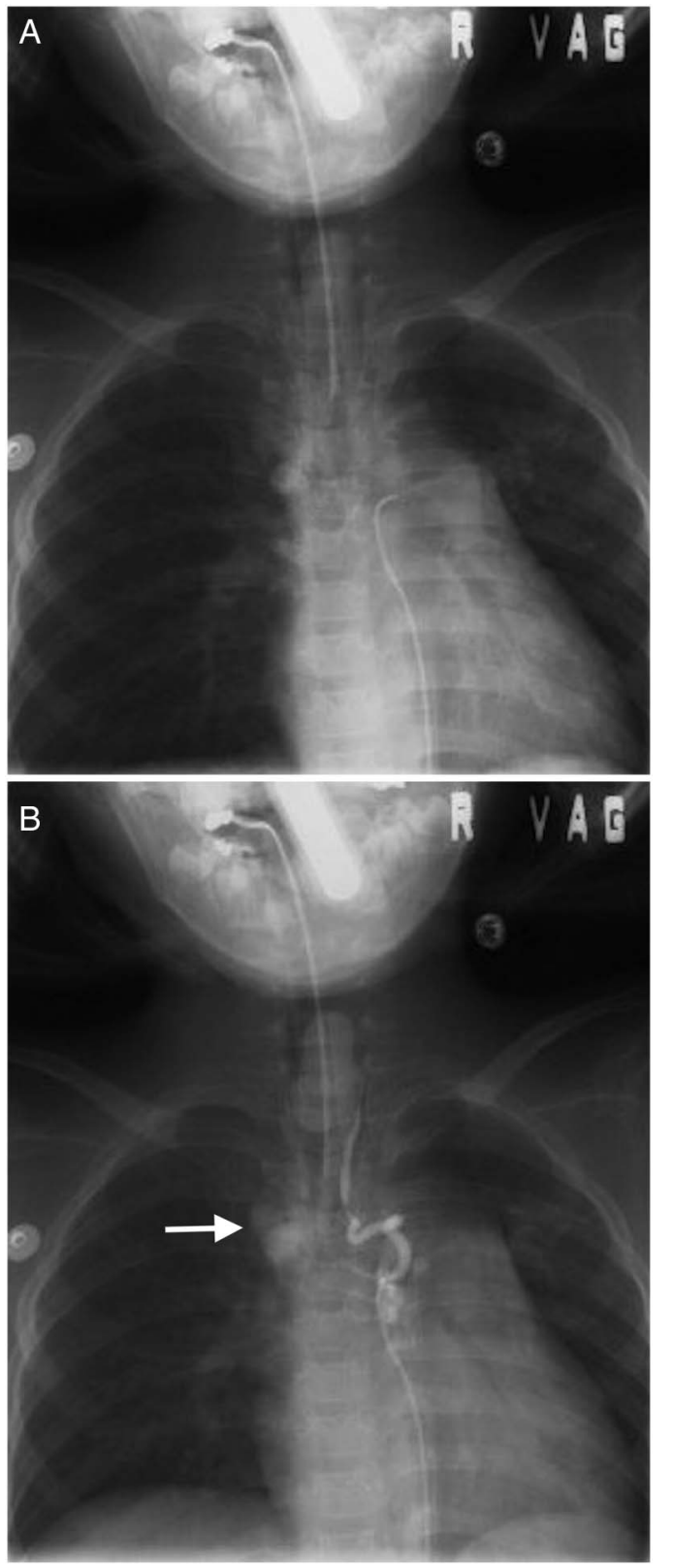

Figure 1 Spinal angiography revealed spinal arteriovenous fistula (AVF) (A) before and (B) after. reversible and rapid change in colour of his unilateral chest wall (figure $3 \mathrm{~A}, \mathrm{~B}$ and video 1). Contrast-enhanced CT of the chest on the same location revealed cutaneous vascular malformation (figure 4). The dermatome level exactly also corresponded to the dermatome level of spinal AVF.

Valsalva manoeuvre can augment neurological symptoms in intraspinal neurological process such as a large disc, tumour or spinal AVF. ${ }^{1}$ Symptoms of spinal AVF usually involve leg weakness or paraparesis $(96 \%)$, sensory numbness or paresthesias $(90 \%)$, urinary incontinence or retention $(82 \%)$ and pain $(55 \%){ }^{2}$

According to the previous report, the spinal cord symptoms were reported to be aggravated and precipitated by Valsalva manoeuvre, trauma, pregnancy, postural changes, increase in body temperature or muscular effort. ${ }^{3}$

The finding seen in our patient can be explained by the transient congestion of blood flow induced by rapid increase in intrathoracic pressure by the manoeuvre on top of the cutaneous and spinal anomalous vascular flow.

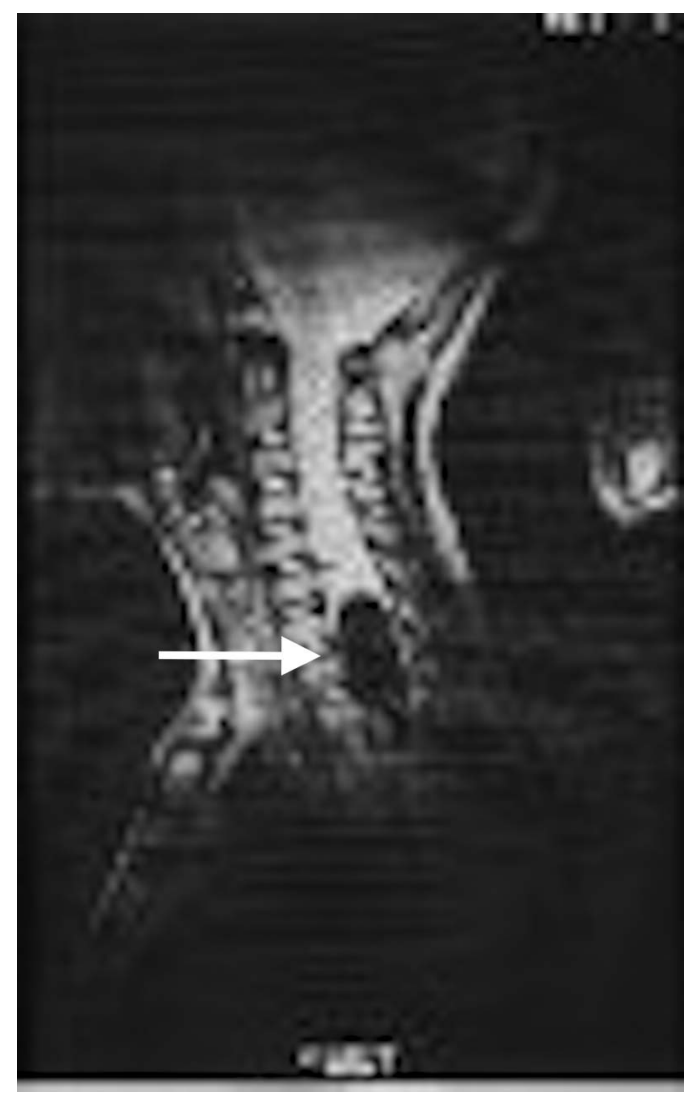

Figure 2 Spinal MRI showed spinal arteriovenous fistula. 

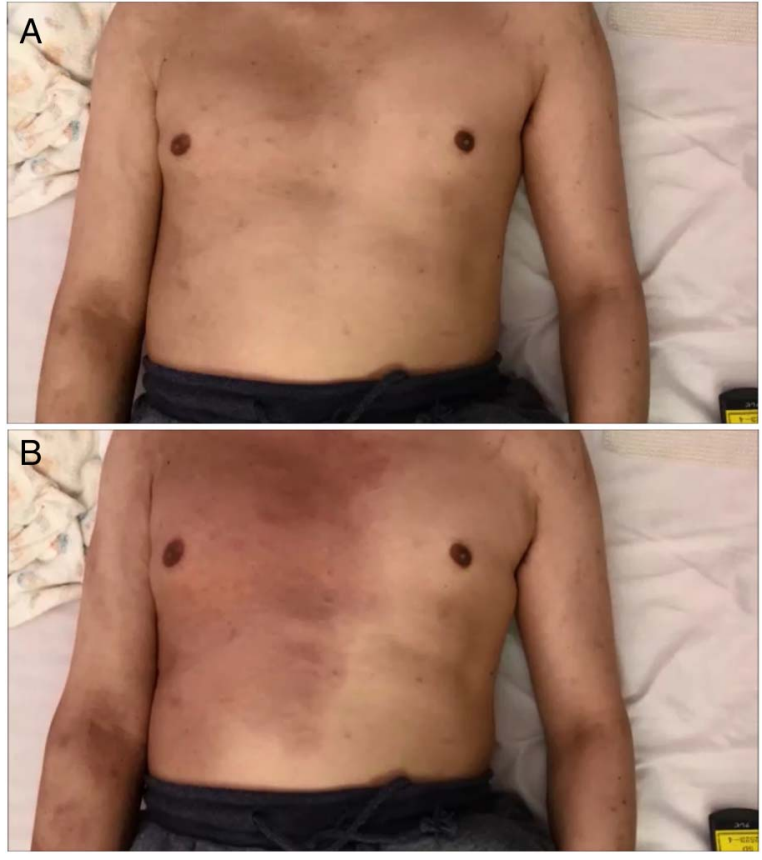

Figure 3 (A) Skin colour of his chest wall before Valsalva manoeuvre. (B) Valsalva manoeuvre induced a reversible and rapid change in colour of his unilateral chest.

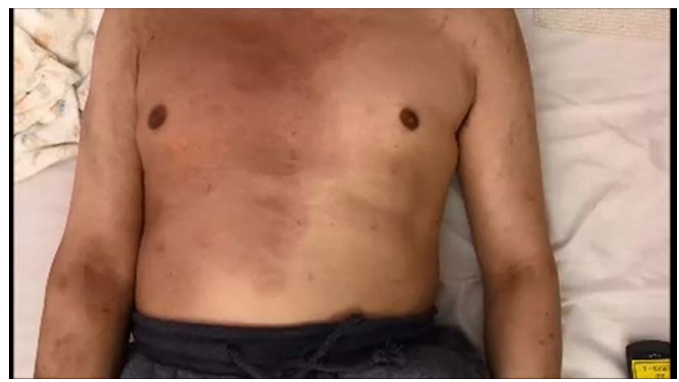

Video 1 Skin colour change during Valsalva manoeuvre.

To the best of our knowledge, this is the first case of the unique physical finding elucidated by Valsalva manoeuvre. This report also suggests a new aspect of Valsalva manoeuvre.

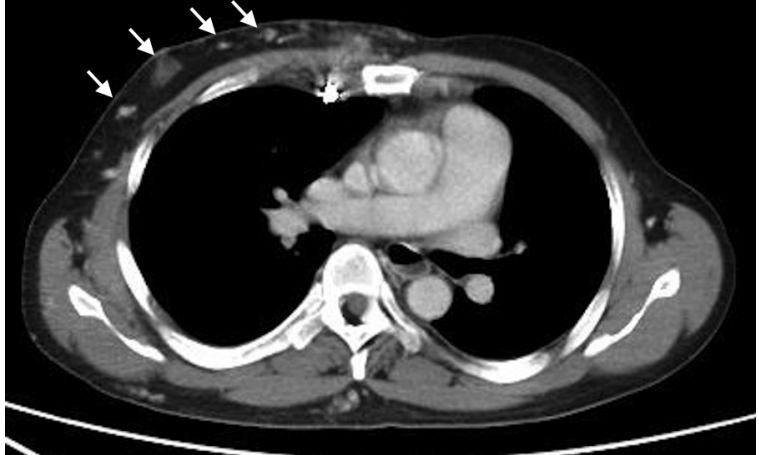

Figure 4 Chest CT with contrast revealed cutaneous vascular malformation in the right chest wall.

\section{Learning points}

- Valsalva manoeuvre can augment neurological symptoms in intraspinal neurological process such as a large disc, tumour or spinal arteriovenous fistula.

- The spinal cord symptoms were reported to be aggravated and precipitated by Valsalva manoeuvre, trauma, pregnancy, postural changes, increase in body temperature or muscular effort.

- A reversible and rapid change in colour of unilateral chest wall with Valsalva manoeuvre can be a key to suspect vascular malformation.

Contributors All authors conceived the paper. $\mathrm{KH}$, TS and TH supervised the paper. All authors participated in writing of the paper, and TS approved the final version.

Competing interests None declared.

Patient consent Obtained.

Provenance and peer review Not commissioned; externally peer reviewed.

\section{REFERENCES}

1 Bartleson JD, Gordon Deen H. Spine disorders: medical and surgical management. Cambridge: University Press, 2009.

2 Van Dijk JM, TerBrugge KG, Willinsky RA, et al. Multidisciplinary management of spinal dural arteriovenous fistulas: clinical presentation and long-term follow-up in 49 patients. Stroke 2002;33:1578-83.

3 Singhal $A B$, Drago $S$, Sheth $S G$, et al. Ruptured type III cervical spinal cord arteriovenous malformation as a cause of acute quadriparesis. J Assoc Physicians India 1995:43:565-6.

Copyright 2017 BMJ Publishing Group. All rights reserved. For permission to reuse any of this content visit http://group.bmj.com/group/rights-licensing/permissions.

BMJ Case Report Fellows may re-use this article for personal use and teaching without any further permission.

Become a Fellow of BMJ Case Reports today and you can:

- Submit as many cases as you like

- Enjoy fast sympathetic peer review and rapid publication of accepted articles

- Access all the published articles

- Re-use any of the published material for personal use and teaching without further permission

For information on Institutional Fellowships contact consortiasales@bmjgroup.com

Visit casereports.bmj.com for more articles like this and to become a Fellow 